\title{
Laying Hen Performance and Yolk lodine, Cobalt and Iron Content Increased by Dietary Supplementation of Potassium lodide, Vitamin B12 and Ferrous Sulfate
}

\section{Mir Nima Aghdashi}

Department of animal science, maragheh branch, islamic azad university, maragheh

Ali Nobakht ( $\sim$ anobakht20@yahoo.com )

Islamic Azad University of Maragheh https://orcid.org/0000-0003-1145-2646

Yousef Mehmannavaz

Department of animal science, maragheh branch, islamic azad university, maragheh

\section{Research Article}

Keywords: Cobalt, Ferrous sulfate, lodine, yolk, Vitamin B12.

Posted Date: May 24th, 2021

DOl: https://doi.org/10.21203/rs.3.rs-485188/v1

License: (c) (1) This work is licensed under a Creative Commons Attribution 4.0 International License.

Read Full License 


\title{
Laying hen performance and yolk Iodine, Cobalt and Iron content increased by dietary supplementation of Potassium iodide, Vitamin $B_{12}$ and Ferrous sulfate.
}

\author{
Mir Nima Aghdashi ${ }^{1}$. Ali Nobakht ${ }^{1}$. Yousef Mehmannavaz $^{1}$
}

the date of receipt and acceptance should be inserted later

Abstract In this experiment, 320 laying hens of HyLine W-36 strain were used in a $2 \times 2 \times 2$ factorial arrangement with 8 treatments with 8 birds in each pen, including 0 and $400 \mathrm{mg} . \mathrm{kg}$ of iron salt $(\mathrm{Fe}), 0$ and 450 mg.kg of iodide $(I)$ and 0 and $0.1 \mathrm{mg} . \mathrm{kg}$ of vitamin B12 in 5 replicates and replicate in from 26 to 39 weeks in a completely randomized design. Dietary experiments had significant effects on the performance of laying hens at the end of the experiment period $(P<0.05)$. The use of $I, B_{12}$ and $F e$ salts had significant effects on the content of these microelements of egg yolks in the main effects and interactions $(P<0.05)$. In the interaction of $F e$ and $I$, the use of $450 \mathrm{mg} . \mathrm{kg}$ of $I$ and 0 level of $F e$ increased the $I$ content of egg yolks $(P<0.05)$. In 400 mg.kg of $F e$ combined with $I$, or the use of $400 \mathrm{mg} . \mathrm{kg}$ of $F e$ with 0 level of iodine salt caused a sharp decrease in the $I$ content of eggs $(P<0.05)$. Supplementation of laying diets with $F e$ and $I$ had no significant effects on egg yolk content of $\mathrm{Fe}$ and Cobalt $(\mathrm{Co})(P>0.05)$. However, $I$ content in yolk was significantly reduced $(P<0.05)$. In the interaction of treatments containing $F e$ and vitamin $B_{12}$, the lowest amount of $C o$ and the highest level of $I$ were observed at the 0 level of both of these supplements $(P<0.05)$ whereas, the combined

*Correspondence: Ali Nobakht

anobakht20@yahoo.com

Mirnima Aghdashi

nima136312@gmail.com

Yousef Mehmannavaz

mehman10@iau-maragheh.ac.ir

1 Department of Animal Science, Maragheh Branch, Islamic Azad University, Maragheh, Iran. use of $F e$ and vitamin $B_{12}$ increased the level of cobalt and decreased the iodine content of eggs $(P<0.05)$. Interactions of $I$ and vitamin $B_{12}$ showed the lowest levels of $I$ and cobalt at 0 levels of these two salts in hens' diets, while the combined use of these salts increased the iron, cobalt and iodine content of eggs $(P<0.05)$. In the three-way effects between these salts, iron content, cobalt of eggs increased and the highest amount of iodine was observed in the third treatments which contained iodine without vitamin $B_{12}$ and iron $(P<0.05)$. Treatments had no significant effects on cobalt content of eggs $(P<0.05)$. Overall results showed that the use of iron, iodine, and vitamin $B_{12}$ salt supplements has improved the performance of hens, as well as the egg content, including iron, iodine, and cobalt, and improved some of the economic characteristics of hens.

Keywords Cobalt, Ferrous sulfate, Iodine, yolk, Vitamin $B_{12}$.

\section{Introduction}

Nutrition of laying hens can be precisely divided into different phases according to the genetic and productions of birds at different climate conditions. The iron is of great importance to animals' good growth and production, such as laying hens. It scientifically is proven that the poultry need for iron varies from 75 to 80 ppm.kg of feed [1]. NRC (1994) recommends for HyLine W-36 that the iron content in the feed should be 80 ppm for each day. Minerals and vitamins exhibit several functions in different cells and organs of animals and men, including antioxidant activities with the ability to improve internal and external quality of eggs. Iron $(F e)$ is one of the important biological elements for poultry 
as well as men. The involved biochemical processes include electron transport, peroxidase, and catalase activities, oxygen transport and storage (hemoglobin and myoglobin) porphyrin metabolism, collagen synthesis, lymphocyte and granulocyte function and neurotransmitter anabolism and catabolism [2].

Iodine is an essential microelement for humans and animals, and it is required for the synthesis of triiodothyronine, thyroid hormones thyroxine, and iodinated amino acid tyrosine. The deficiency of Iodine reduces the production of thyroid hormones in animals and humans causing morphological and functional to change the thyroid gland and reduction of the secretion of thyroxin [3]. Naber and Squires (1991) showed that it is also possible to increase the content of an egg through using vitamin $B_{12}$. By increasing the feed dose of vitamin $B_{12}$ from 0.5 to $16 \mu \mathrm{g} / \mathrm{kg}$ (28 to $70 \mathrm{wk}$ ) by using commercial white leghorn flocks, there was a 11-folding increase in yolk vitamin $B_{12}$ level (in normal eggs, the level of $B_{12}$ in egg yolk is $0.4 \mu \mathrm{g} / \mathrm{kg} / 100 \mathrm{~g}$ ).

Many studies related to egg vitamin and minerals enrichment through nutrition experiments, with special attention paid to fat-soluble vitamins $E, A, D$, but also to vitamin $B_{12}$ and folic acid are now available [4-7]. Findings have classified the transfer effectiveness of vitamins from the diet of laying hens to yolk, which was very high for vitamin $A$, high for riboflavin, pantothenic acid, biotin, and vitamin $B_{12}$, medium for vitamin $D_{3}$ and $E$, and low for vitamin $K$, thiamine and folacin, however, the combined effects of vitamin premix and vitamins on vitamin and mineral deposition in eggs are rare [8]. Therefore, the purpose of this study was to investigate the possibility of enhancing Potassium iodide, Vitamin $B_{12}$, and Ferrous sulfate administration on yolk, Iodine, $(\mathrm{Co})$ and $\mathrm{Fe}$ content in eggs through their supplementation in laying hens' diets and to determine the effects of these microelements on egg quality parameters and poultry production performance.

\section{Material and Methods}

\subsection{General}

320 Hy-Line W-36 hens ages from 26 to 39 weeks (1.48$1.52 \mathrm{~kg}$ ) were kept for 13 weeks in a completely randomized design with $2 \times 2 \times 2$ factorial arrangements. West Azerbaijan Province Khoy city in Aghlary farm center in 18th November 2019 until 17th January 2020. Diets included 8 treatments at the levels (0 and $400 \mathrm{mg} . \mathrm{kg}$ of $\mathrm{Fe}$ ), (0 and $450 \mathrm{mg} . \mathrm{kg}$ of $I$ ), and 0 and $0.1 \mathrm{mg} . \mathrm{kg}$ of vitamin $B_{12}$ were prepared and used. Each experiment group consisted of five replicates with 8 birds in each replicate. Two adjacent cages, each cages dimension $(40 \times 20 \times 25 \mathrm{~cm})$ containing 4 hens were considered as the experimental group. Hens received $16 \mathrm{~h} / \mathrm{d}$ of artificial lighting and ventilation at a natural ambient temperature. Feed and water were provided ad libitum throughout the experiment period. The experiment was conducted in poultry farm in Khoy city named Aghlari in 18th November 2019 until $17^{\text {th }}$ January 2020. After 10 days of adaptation, data such as number of eggs, eggs weight, loss rate were collected and the amount of feed intake was measured daily. The feed conversion ratio was calculated based on grams of feed intake per gram of eggs produced. Produced eggs were collected daily and calculated as a percentage of egg production for each hen. The produced eggs throughout the week were used to calculate the weekly average of produced eggs. After 13 weeks, 20 eggs were randomly selected from each treatments and sent to The laboratory measurements of cobalt and $F e$ in the research department of chromatography, Iranian Academic Center for Education, Culture and Research (ACECR), Urmia,West Azerbayjan, Iran.

\subsection{Experimental diets}

A corn-soybean meal basal diet was formulated according to nutrient requirements of National Research Council (1994) for laying poultry (Table 1). Experimental diets were obtained by supplementing the basal diet with synthetic 0 and $400 \mathrm{mg} . \mathrm{kg}$ of $F e, 0$ and $450 \mathrm{mg} \cdot \mathrm{kg}$ of $I$, and 0 and $0.1 \mathrm{mg} . \mathrm{kg}$ of vitamin $B_{12}$.

\subsection{Chemicals for analysis}

\subsubsection{Laboratory process for the evaluation of iron and cobalt in egg samples}

To analyze the chemicals, $2.5 \mathrm{~g}$ of the yolk sample was weighed and placed inside the crucible. The crucible was then placed inside the kiln heated to temperature $550^{\circ} \mathrm{C}$ for ashing. After preparing the whole ash, the crucibles were allowed to cool, then a solution of nitric acid was used to dissolve the ash on the heater at $75^{\circ}$ C. Then the contents of the cruise were transferred into a $25 \mathrm{cc}$ balloon with a funnel and the cruise was rinsed several times with distilled water and transferred to the balloon. The laboratory measurements of cobalt and $F e$ were done in the research department of chromatography, Iranian Academic Center for Education, Culture and Research (ACECR), Urmia, Iran. 
Table 1 Ingredients and chemical composition of basal diet of laying hens (\%, as feed basis)..

\begin{tabular}{ll}
\hline Ration & $\%$ \\
\hline Corn & 58.10 \\
Soybean Meal & 22.18 \\
Oyster shell & 10.00 \\
Wheat Bran & 6.00 \\
Soybean Oil & 2.0 \\
Dical. Phos & 1.60 \\
Mineral Premix $1^{1}$ & 0.03 \\
Vitamin Premix2 ${ }^{2}$ & 0.03 \\
L-Lysine HCl & 0.025 \\
Common Salt & 0.025 \\
DL-Methioni & 0.013 \\
Total & 100 \\
& \\
M.E & 2700 \\
Protein & 15.88 \\
Calcium & 4.42 \\
Avail Phosphorus & 0.52 \\
Sodium & 0.31 \\
Methionine & 0.58 \\
Lysine & 0.94 \\
Methionine + Cysteine & 1.36 \\
Arginine & 1.06 \\
Linoleic Acid & 1.91 \\
Threonine & 0.68 \\
Tryptophan & 0.31 \\
\hline
\end{tabular}

${ }^{1}$ Mineral supplement per $\mathrm{kg}$ of diet: $2.4 \mathrm{mg}$ of copper, 0.34 $\mathrm{mg}$ of iodine, $30 \mathrm{mg}$ of iron, $29.76 \mathrm{mg}$ of manganese, $0.08 \mathrm{mg}$ of selenium, $25.87 \mathrm{mg}$ of zinc.

${ }^{2}$ Vitamin supplement per $\mathrm{kg}$ of diet: 3520Iu Vitamin $A, 0.59$ $\mathrm{mg}$ vitamin $B_{1}, 1.6 \mathrm{mg}$ vitamin $B_{2}, 13.86 \mathrm{mg}$ niacin, $13.3 \mathrm{mg}$ pantothenic acid, $1 \mathrm{mg} B_{6}, 0.06 \mathrm{mg}$ biotin, $80 \mathrm{mg}$ choline, $0.004 \mathrm{mg}$ vitamin $B_{12}, 0.19 \mathrm{mg} B_{9}, 1000 \mathrm{IU}$ vitamin $D_{3}, 8.8$ IU vitamin $E, 0.88 \mathrm{mg} K_{3}$, all calculations are evaluated based on the requirements of (1994) NRC.

\subsubsection{Preparing a standard solution}

The standard 1000 ppm of iron and cobalt was prepared and the atomic absorption rate of the samples was recorded by using the atomic absorption apparatus made in Perkin Elmer model: analyst 800. After reading the standard adsorption, its amount was calculated using calibration and was expressed in $100 \mathrm{~g}$ of the sample.

\subsubsection{Laboratory process for the evaluation Iodine in egg samples}

After 13 weeks, 20 eggs were randomly selected from each treatments and sent to the relevant laboratory in order to calculate the iodine content in egg yolk. This was carried out almost exclusively by using kinetic spectrophotometric method called the Sandell-Kolthoff reaction $[9,10]$. The laboratory measurements of Iodine were done in the research department of chromatography, Iranian Academic Center for Education, Culture and Research (ACECR), Urmia, Iran.

\section{Statistical analysis}

Data were subjected to using the PROC GLM procedure of SAS 9.4 software. Data were log-transformed before analyzing in case of unequal variances. Means were compared using Tukey's multiple range test at $\alpha$ $=0.05$.

\section{Results}

\subsection{Egg Internal Micronutrients Composition}

The effects of using different experimental supplements on egg internal micronutrients Composition are shown in Table 2. Regarding the main effects of iron and iodine salts and vitamin $B_{12}$, it was observed that only iron had not a significant effect $(P>0.05)$ on $F e$ Composition but $B_{12}$ and iodine salts increased the levels of $C o$ and $I$ in egg yolk respectively $(P<0.05)$. In the interaction of $F e$ and $I$, the use of $450 \mathrm{mg} / \mathrm{kg}$ of $I$ along with zero level of $F e$, increased the $I$ content of eggs $(P<0.05)$. If $400 \mathrm{mg} / \mathrm{kg}$ of $F e$ combined with $I$, or the use of $400 \mathrm{mg} / \mathrm{kg}$ of $F e$ with zero level of iodine salt caused a sharp decrease in the $I$ content of eggs $(P<0.05)$. Supplementation of laying diets with $F e$ with $I$ had no significant effects on egg $F e$ and Cobalt $(C o)$ content $(P>0.05)$. But the $I$ content in yolk was significantly reduced $(P<0.05)$. In the interaction of treatments containing $\mathrm{Fe}$ and vitamin $B_{12}$ supplementation, the lowest amount of $C o$ and the highest level of $I$ were observed at the 0 level of both of these supplements $(P<0.05)$. While the combined use of $F e$ and vitamin $B_{12}$ increased the level of cobalt and decreased the iodine content of eggs $(P<0.05)$. Interactions of $I$ and vitamin $B_{12}$ showed the lowest levels of $I$ and cobalt at zero levels of these two salts in chickens' diets, while the combined use of these salts increased the iron, cobalt and iodine content of eggs $(P<0.05)$. In the three-way effects between these salts, iron content, cobalt of eggs increased and the highest amount of iodine was observed in the third treatment which contained iodine without vitamin $B_{12}$ and iron $(P<0.05)$. Treatments had no significant effects on cobalt content of eggs $(P<0.05)$.

\subsection{Performance}

The effects of using different experimental supplements on performance of laying hens are shown in Table 3, the use of iron salt in the diet for laying hens has significantly increased the percentage of egg production and 
Table 2 Effect of dietary Potassium iodide, Vitamin $B_{12}$ and Ferrous sulfate administration on yolk, Iodine, Cobalt and Iron content.

\begin{tabular}{|c|c|c|c|c|}
\hline & Effects & $\begin{array}{l}\text { Iron } \\
\text { Available }(\mathrm{mg} / \mathrm{kg})\end{array}$ & $\begin{array}{l}\text { Cobalt } \\
\text { Available (mg/kg) }\end{array}$ & $\begin{array}{l}\text { Iodine } \\
\text { Available }(\mathrm{mg} / \mathrm{kg})\end{array}$ \\
\hline \multicolumn{5}{|l|}{ Ferrum } \\
\hline & 0 & 11.4025 & 0.1342 & $0.7073^{b}$ \\
\hline & 400 & 12.9721 & 0.1433 & $0.5449^{a}$ \\
\hline & SEM & 0.8079 & 0.0151 & 0.0083 \\
\hline & $\mathrm{P}$-value & 0.1720 & 0.6703 & $<.0001$ \\
\hline \multicolumn{5}{|l|}{ Iodin } \\
\hline & 0 & $10.7247^{b}$ & 0.1216 & $0.4175^{b}$ \\
\hline & 450 & $13.6499^{a}$ & 0.1559 & $0.8347^{a}$ \\
\hline & SEM & 0.8079 & 0.0151 & 0.0083 \\
\hline & $\mathrm{P}$-value & 0.0116 & 0.1096 & $<.0001$ \\
\hline \multicolumn{5}{|l|}{$B_{12}$} \\
\hline & 0 & 12.1412 & $0.0868^{b}$ & 0.6183 \\
\hline & 0.1 & 12.2334 & $0.1907^{a}$ & 0.6338 \\
\hline & SEM & 0.8079 & 0.0151 & 0.0083 \\
\hline & $\mathrm{P}$-value & 0.9358 & $<.0001$ & 0.19 \\
\hline \multicolumn{5}{|c|}{ Ferrum $\times$ Iodin } \\
\hline & $0 \times 0$ & $8.2478995^{b}$ & 0.1351 & $0.3817^{d}$ \\
\hline & $0 \times 450$ & $14.5571011^{a}$ & 0.1334 & $1.0328^{a}$ \\
\hline & $400 \times 0$ & $13.2014874^{a}$ & 0.1082 & $0.4533^{c}$ \\
\hline & $400 \times 450$ & $12.7426356^{a}$ & 0.1784 & $0.6365^{b}$ \\
\hline & SEM & 1.1836 & 0.0220 & 0.0122 \\
\hline & $\mathrm{P}$-value & 0.0036 & 0.0936 & $<.0001$ \\
\hline \multicolumn{5}{|c|}{ Ferrum $\times B_{12}$} \\
\hline & $0 \times 0$ & 11.5197 & $0.0789^{c}$ & $0.7485^{a}$ \\
\hline & $0 \times 0.1$ & 11.2853 & $0.1896^{a b}$ & $0.6660^{b}$ \\
\hline & $400 \times 0$ & 12.7627 & $0.0947^{b c}$ & $0.4880^{d}$ \\
\hline & $400 \times 0.1$ & 13.1815 & $0.1919^{a}$ & $0.6017^{c}$ \\
\hline & SEM & 1.1836 & 0.0220 & 0.0122 \\
\hline & $\mathrm{P}$-value & 0.7756 & 0.7516 & $<.0001$ \\
\hline \multicolumn{5}{|c|}{ Iodin $\times B_{12}$} \\
\hline & $0 \times 0$ & $12.4388^{a}$ & $0.0728^{b}$ & $0.3612^{d}$ \\
\hline & $0 \times 0.1$ & $9.0106^{b}$ & $0.1704^{a}$ & $0.4737^{c}$ \\
\hline & $450 \times 0$ & $11.8436^{a}$ & $0.1008^{a b}$ & $0.8754^{a}$ \\
\hline & $450 \times 0.1$ & $15.4562^{a}$ & $0.2111^{a}$ & $0.7940^{b}$ \\
\hline & SEM & 1.1836 & 0.0220 & 0.0122 \\
\hline & $\mathrm{P}$-value & 0.0025 & 0.7667 & $<.0001$ \\
\hline \multicolumn{5}{|c|}{ Ferrum $\times$ Iodin $\times B_{12}$} \\
\hline & $0 \times 0 \times 0$ & $5.7323^{c}$ & 0.0742 & $0.3157^{f}$ \\
\hline & $0 \times 0 \times 0.1$ & $10.7635^{b c}$ & 0.1959 & $0.4476^{e}$ \\
\hline & $0 \times 450 \times 0$ & $17.3070^{a b}$ & 0.0835 & $1.1814^{a}$ \\
\hline & $0 \times 450 \times 0.1$ & $11.8072^{b c}$ & 0.1833 & $0.8843^{b}$ \\
\hline & $40 \times 0 \times 0$ & $19.1452^{a}$ & 0.0714 & $0.4067^{e}$ \\
\hline & $40 \times 0 \times 0.1$ & $7.2578^{c}$ & 0.1450 & $0.4999^{e}$ \\
\hline & $40 \times 450 \times 0$ & $6.3801^{c}$ & 0.1180 & $0.5693^{d}$ \\
\hline & $40 \times 450 \times 0.1$ & $19.1051^{a}$ & 0.2389 & $0.7036^{c}$ \\
\hline & SEM & 1.6101 & 0.0300 & 0.0166 \\
\hline & $\mathrm{P}$-value & $<.0001$ & 0.4177 & $<.0001$ \\
\hline
\end{tabular}

$a, b, c, d, e$, and $f$ means within each column with different superscripts are significantly different $(P<0.05)$.

egg mass, but reduced and improved the conversion ratio $(P<0.05)$, Iron did not have any significant effect on the average egg weight and Feed Intake $(P>0.05)$. Generally, iron in the diet for laying hens improved economical traits. This effects was not observed for iodine salt and vitamin $B_{12}$. The use of these microelements did not have any significant effects on the performance of laying hens in this study (Table 3).

However, in the case of bilateral effects, the situation was slightly different. Concomitant use of iron with iodine increased the percentage of egg production compared to when iodine was used alone in the diet and shows that dietary iron improved the iodine yield of the diet. This trend was also achieved for egg mass production, and iron improved iodine efficiency in the diet. The feed conversion ratio, which is one of the important traits of laying hens, was affected by these two microelements and was improved. But this reduction was not significant. However, it was decreased by $5 \%$, which is numerically significant. The combined use of 
Table 3 Effect of dietary Potassium iodide, Vitamin $B_{12}$ and Ferrous sulfate administration on laying hens performance.

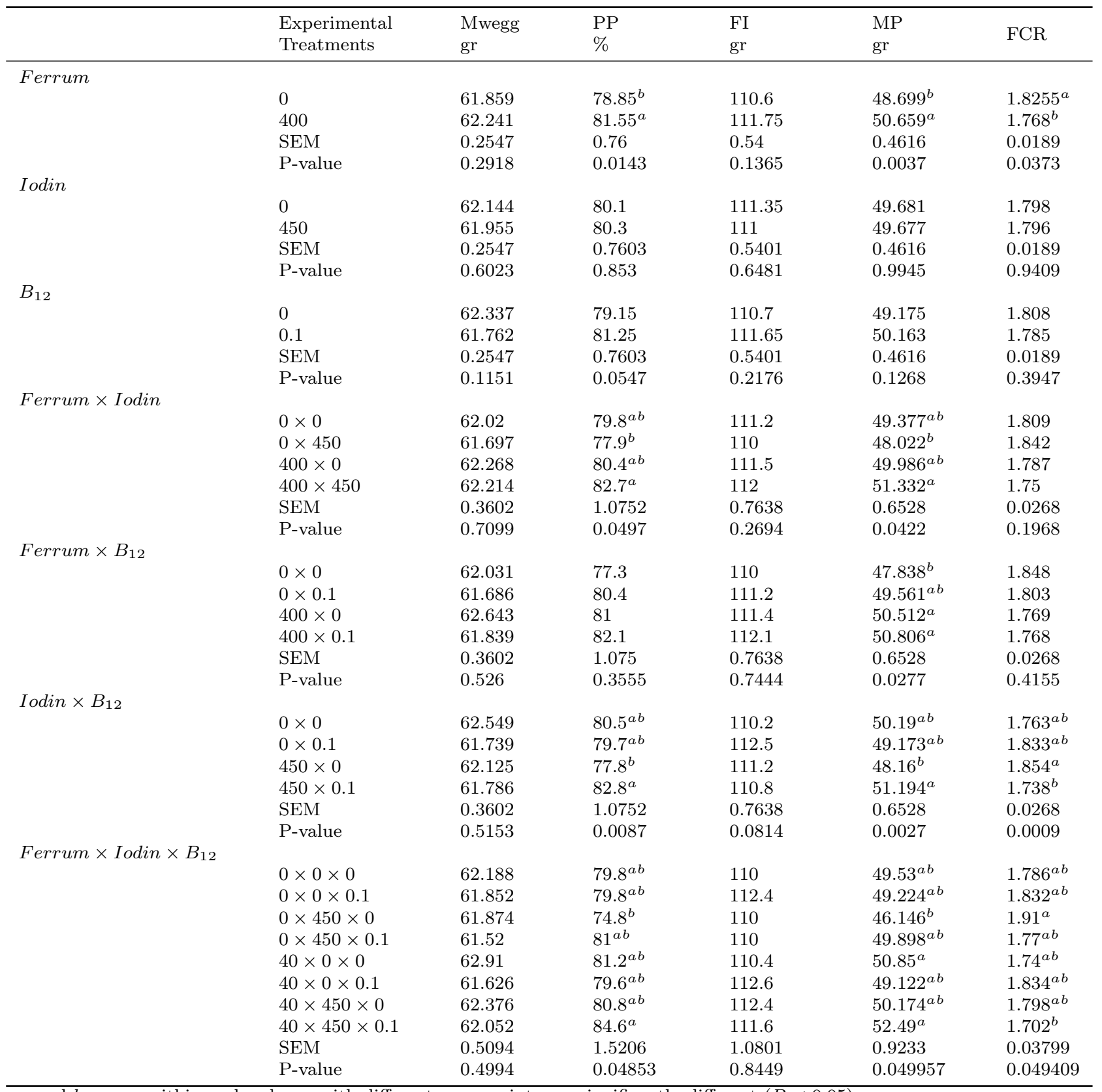

$a$ and $b$ means within each column with different superscripts are significantly different $(P<0.05)$.

iron and vitamin increased the trait of egg mass by 3 grams, which is economically important, and the trait of conversion factor was decreased by $4 \%$, which was not statistically significant.

The simultaneous use of iodine and vitamin improved the performance of economical traits of laying hens. Interestingly, it is seen again that vitamin improved the effect of reduced yield due to iodine and increased the percentage of production, egg mass and feed conversion ratio decreased significantly. The statistical probability of feed conversion ratio is lower than $0.0009(p<0.0009)$ which is statistically significant and needs further research ( $6 \%$ reduction).

The previous trend regarding the effect of iodine on production percentage, egg mass and feed conversion ratio can also be seen in this part of the table, and the simultaneous use of these 3 microelements increases the production percentage of egg mass, and the reduction of feed conversion ratio is statistically significant. However, none of the experimental treatments changed significantly compared to the control group and these 
effects are only compared to other microelements compared to the use of iodine alone.

\section{Discussion}

During 28-36 weeks of age, there were no significant differences about $F I$ [11] and in another study it was observed that feed intake decreased significantly with iron supplementation in broiler hens' diets [12]. In this study, however, there were no significant effect of Iron on FI. In agreement with the present study, some researchers reported similar results on Mandarah layer hens and Gimmezah layer as local strains [11, 13, 14]. Supplementing poultry diets with Iodine had no significant effect on production of eggs and egg mass [15-17]. However, Christensen et al., (1991) reported that egg weight increased to $3.5 \mathrm{mg} . \mathrm{kg}$ due iodine supplementation. They reported egg weight increased only in British United Turkeys and no differences in egg weight in Nicholas Turkeys were reported. A decrease in production of egg and performance after 12 weeks of production was reported when a diet without $B_{12}$ was used [18]. Eggs were smaller when no vitamin $B_{12}$ was added and specific weight was inversely proportional to the size of the egg, generally Vitamin $B_{12}$ increased egg size [19].

Because of improved production traits in new strains of poultry, it seems that microelements requirement recommended by NRC for laying poultry needs to be revised. Thus, to meet the real requirement of minerals and vitamins in industrial poultries, it is necessary to conduct some relevant studies. Egg yolk has a good potential for enrichment by the supplemented diets with different minerals and vitamins. It is possible to significantly increase vitamin content of eggs through fortification of the laying hen diet with synthetic vitamins, and table eggs can be changed to one of the rich sources of natural synthetic microelements [20-26]. The cobalt is not considered as an essential mineral for hens even though it may consist as much as $4 \%$ of the composition of the molecule of vitamin $B_{12}$. Therefore, in this study the cobalt is investigated as an indicator of $B_{12}$. Table 2 shows that when laying hens diet is supplemented with $B_{12}$, the level of cobalt increases significantly. Adding vitamin $B_{12}$ to the diet had no effect $(P>0.05)$ on cobalt concentration in the liver and yolk [19].

Furthermore, the levels of $F e$ and $I$ were improved and increased in egg yolk when the levels of these microelements in diets were elevated. When $F e$ and $I$ are both added to the salt, the $I$ is transformed to elemental $I$, which can vanish, and therefore lost rapidly. Earlier trials by Burgie et al (1986) indicated that the iodine moiety of the double-fortified sait was unstable due to the loss of iodine as a result of evaporation and catalytic oxidation of $I$ - to $I^{2}$ in the presence of ferrous ions and air oxygen [27]. Anemia and goiter are the two major nutrition-related illnesses which lead to serious consequences on mental and physical development in one in three people. The present study showed that by increasing the levels of $\mathrm{Fe}$ in the diet, the amount of iodine in the egg decreases, indicating the antagonistic effect of iron on iodine. On the other hand, these two elements are among the essential nutritional needs of society. According to Table 3, in order to enrich eggs with iron, special attention should be paid to the levels of iodine in the diet since by reducing the iodine in eggs, the nutritional value of this food decreases.

\section{Conclusion}

Generally, the use of iron, iodine, and vitamin $B_{12}$ salt supplements has increased the performance of chickens, as well as the egg content, including iron, iodine, and cobalt, and improved some of the economic characteristics of chickens. This study showed that in order to enrich eggs yolk with iron, special care should be paid to the levels of iodine in the poultry diets. This study showed that when laying hen's diet supplemented with $B_{12}$ the level of cobalt raised significantly.

\section{Declarations}

\subsection{Funding}

The authors did not receive support from any organization for the submitted work.

\subsection{Conflicts of interest}

The authors have no conflicts of interest to declare that are relevant to the content of this article.

\subsection{Ethics approval}

This is an observational study. The Maragheh University (IR.MARAGHEHPHC.REC) Research Ethics Committee has confirmed that no ethical approval is required.

\subsection{Authors' Contributions}

In this paper, the Field studies, project designer and executor, project implementation, sample collection, laboratory recording and coordination are done by Dr. Mir 
Nima Aghdashi. Dr. Ali Nobakht contributes to article writing, editing, and finalizing the article. Data Analyzing and preparing article's tables are done by Dr. Yousef Mehmannavaz.

\subsection{Consent to participate}

Not applicable.

\subsection{Consent for publication}

Not applicable.

7.7 Availability of data and material

Not applicable.

7.8 Code availability

Not applicable.

\section{References}

1. P. Davis, L. Norris, F. Kratzer, Iron utilization and metabolism in the chick, The Journal of nutrition 94 (3) (1968) 407-417.

2. N. R. Council, Nutrient Requirements of Poultry: Ninth Revised Edition, 1994, The National Academies Press, Washington, DC, 1994.

3. I. WHO, Uncf. assessment of iodine deficiency disorders and monitoring their elimination.-2-nd ed (2001).

4. M. Macit, M. Karaoglu, S. Celebi, N. Esenbuga, M. A. Yoruk, A. Kaya, Effects of supplementation of dietary humate, probiotic, and their combination on performance, egg quality, and yolk fatty acid composition of laying hens, Tropical Animal Health and Production 53 (1) (2021) 1-8.

5. A. E. Al-saffar, Y. A. Attia, M. B. Mahmoud, H. S. Zewell, F. Bovera, Erratum to: Productive and reproductive performance and egg quality of laying hens fed diets containing different levels of date pits with enzyme supplementations, Tropical Animal Health and Production 46 (1) (2014) 289-289.

6. J. Rattanawut, O. Pimpa, K. Venkatachalam, K.-e. Yamauchi, Effects of bamboo charcoal powder, bamboo vinegar, and their combination in laying hens on performance, egg quality, relative organ weights, and intestinal bacterial populations, Tropical Animal Health and Production 53 (1) (2021) 1-7.

7. M. Abd El-Hack, M. Alagawany, M. Chaudhry, M. Saeed, E. Ahmad, S. El-Sayed, Does the gradual increase in dietary zinc oxide supplementation can affect egg quality, serum indices, and productive performance of laying hens?, Tropical animal health and production 52 (2) (2020) 525-531.
8. E. C. Naber, Modifying vitamin composition of eggs: a review, Journal of Applied Poultry Research 2 (4) (1993) 385-393.

9. J. Bednar, S. ROEHLING, S. Vohnout, Contribution to determination of protein-bound iodine in the blood serum, Ceskoslovenska farmacie 13 (1964) 203.

10. E. Sandell, I. Kolthoff, Micro determination of iodine by a catalytic method, Microchimica Acta 1 (1) (1937) 9-25.

11. N. A. Ramadan, A. S. Omar, A. Bahakaim, S. M. Osman, et al., Effect of using different levels of iron with zinc and copper in layer's diet on egg iron enrichment, Int. J. Poult. Sci 9 (9) (2010) 842-850.

12. J. Cao, X. Luo, P. Henry, C. Ammerman, R. Littell, R. Miles, Effect of dietary iron concentration, age, and length of iron feeding on feed intake and tissue iron concentration of broiler chicks for use as a bioassay of supplemental iron sources, Poultry Science 75 (4) (1996) 495504 .

13. B. M.M, N. El-Sayed, F. Soliman, M. Koslia, The effect of introducing dwarfe gene to mandarah strain on economically important traits.egypt, Poultry Science 15 (1995) 43-71.

14. A.-E. M.A, N. Abdel-Malak, M. Attia, Effect of feeding different levels of herbal anti-heat stress on laying hens during summer time in upperegypt, Applied Sciences 12 (1997) 49-66.

15. A. Saki, M. A. Farisar, H. Aliarabi, P. Zamani, M. Abbasinezhad, et al., Iodine-enriched egg production in response to dietary iodine in laying hens, J. Agric. Technol 8 (4) (2012) 1255-1267.

16. S. Kaufmann, W. Rambeck, Iodine supplementation in chicken, pig and cow feed, Journal of Animal Physiology and Animal Nutrition 80 (1-5) (1998) 147-152.

17. S. Yalcin, Z. Kahraman, S. Yalcin, S. Yalcin, H. Dedeoğlu, Effects of supplementary iodine on the performance and egg traits of laying hens, British poultry science 45 (4) (2004) 499-503.

18. M. W. SQUIRES, E. C. NABER, Vitamin profiles of eggs as indicators of nutritional status in the laying hen: vitamin b12 study, Poultry Science 71 (12) (1992) 2075-2082.

19. R. Kato, A. Bertechini, E. Fassani, C. Santos, M. Dionizio, E. Fialho, Cobalt and vitamin b12 in diets for commercial laying hens on the second cycle of production, Brazilian Journal of Poultry Science 5 (1) (2003) 45-50.

20. T. Sherwood, R. Alphin, W. Saylor, H. White, Folate metabolism and deposition in eggs by laying hens, Archives of biochemistry and biophysics 307 (1) (1993) $66-72$.

21. J. House, K. Braun, D. Ballance, C. O'connor, W. Guenter, The enrichment of eggs with folic acid through supplementation of the laying hen diet, Poultry science 81 (9) (2002) 1332-1337.

22. K. Hebert, G. Tactacan, T. Dickson, W. Guenter, J. House, The effect of cereal type and exogenous enzyme use on total folate content of eggs from laying hens consuming diets supplemented with folic acid, Journal of Applied Poultry Research 20 (3) (2011) 303-312.

23. L. Hoey, H. McNulty, E. M. McCann, K. J. McCracken, J. M. Scott, B. B. Marc, A. M. Molloy, C. Graham, K. Pentieva, Laying hens can convert high doses of folic acid added to the feed into natural folates in eggs providing a novel source of food folate, British journal of nutrition 101 (2) (2008) 206-212.

24. G. Tactacan, M. Jing, S. Thiessen, J. RodriguezLecompte, D. o'Connor, W. Guenter, J. House, Characterization of folate-dependent enzymes and indices of folate status in laying hens supplemented with folic acid or 
5-methyltetrahydrofolate, Poultry science 89 (4) (2010) 688-696.

25. T. Dickson, G. Tactacan, K. Hebert, W. Guenter, J. House, Optimization of folate deposition in eggs through dietary supplementation of folic acid over the entire production cycle of hy-line w36, hy-line w98, and cv20 laying hens, Journal of Applied Poultry Research 19 (1) (2010) 80-91.

26. S. Bagheri, H. Janmohammadi, R. Maleki, A. Ostadrahimi, R. Kianfar, Laying hen performance, egg quality improved and yolk 5-methyltetrahydrofolate content increased by dietary supplementation of folic acid, Animal nutrition 5 (2) (2019) 130-133.

27. M. Sattarzadeh, S. H. Zlotkin, Iron is well absorbed by healthy adults after ingestion of double-fortified (iron and dextran-coated iodine) table salt and urinary iodine excretion is unaffected, The Journal of nutrition 129 (1) (1999) $117-121$. 